\title{
Molecular epidemiology of airway colonisation by Aspergillus fumigatus in cystic fibrosis patients
}

\author{
BERNARD CIMON, FRANÇOISE SYMOENS*, RACHID ZOUHAIR†‡, DOMINIQUE CHABASSE, \\ NICOLE NOLARD*, ALAIN DEFONTAINE† and JEAN-PHILIPPE BOUCHARA
}

Groupe d'Etude des Interactions Hôte-Parasite, Laboratoire de Parasitologie-Mycologie, Centre Hospitalier Universitaire, Angers, France, *Scientific Institute of Public Health-Louis Pasteur, Section of Mycology, Brussels, Belgium and †Laboratoire de Biotechnologie, UPRES 2161 Biocatalyse, Nantes, France

\begin{abstract}
A total of 109 sequential and multiple Aspergillus fumigatus isolates corresponding to 41 samples from seven cystic fibrosis (CF) patients was typed by random amplification of polymorphic DNA (RAPD) with the primer NS3 from the fungal ribosomal gene 18S subunit, and by sequence-specific DNA primer (SSDP) analysis. RAPD typing of the isolates revealed 10 different genotypes, whereas nine genotypes were identified by SSDP. Combination of the two typing methods permitted the differentiation of 25 overall genotypes. The colonisation typing patterns differed greatly between patients colonised for $<1$ year by $A$. fumigatus and long-term colonised patients. Two of three recently colonised patients presented a large number of types even in the same sample, unlike the chronically colonised patients, who harboured a limited number of genotypes. In the latter, the occurrence of a dominant genotype, usually the overall genotype 2 , tended to reflect to the duration of colonisation. Moreover, anti-catalase antibodies to $\mathrm{A}$. fumigatus appeared in most cases to be in response to genotype 2 . These findings suggest that some strains of $A$. fumigatus may be selected during prolonged colonisation of the airways in CF patients.
\end{abstract}

\section{Introduction}

With a prevalence rate of 1 in 2500 in children, cystic fibrosis (CF) is the most common recessively inherited disease among the Caucasian population. Mutations in the gene encoding the chloride channel cystic fibrosis transmembrane regulator result in a dysfunction of the exocrine glands leading especially to abnormal viscosity of the bronchial secretions. The lungs are the main target of the disease and are often infected by different bacteria such as Staphylococcus aureus and Pseudomonas aeroginosa [1]. As a consequence of the resulting broncho-pulmonary epithelial tissue damage, these patients become prone to fungal infections of the airways and, at a more advanced stage of the disease, Aspergillus fumigatus often colonises their respiratory tracts [2].

In the past decade, several DNA typing methods, including restriction fragment-length polymorphism

Received 12 Sept. 2000; revised version received 12 Sept. 2000; accepted 14 Oct. 2000.

†Present address: Départment de Biologie, Faculté des Sciences, Université Moulay Ismail, Meknes, Morocco.
(RFLP) analysis with or without Southern blot hybridisation with various repetitive probes [3-8], PCR-based methods such as random amplification of polymorphic DNA (RAPD) [7-14], sequence-specific DNA primer (SSDP) analysis [15] and analysis by automatic sequencer of PCR-amplified microsatellites [16] have been applied to strain delineation in $A$. fumigatus. They have provided a greater understanding of the epidemiology of invasive pulmonary aspergillosis $[5,7,13,14,17]$ and aspergilloma $[18,19]$. However, little information is available concerning the molecular epidemiology of airways colonisation by $A$. fumigatus in CF patients. Sequential isolates from two patients were typed by Verweij et al. [20]: one patient had a dominant genotype, while different types were successively displayed for the other patient. Similar results were obtained by Rath et al. [21], who analysed 24 isolates from six patients. However, no multiple isolates from the same samples were typed, and their findings were not correlated with clinical data. A better understanding of the airways colonisation by $A$. fumigatus in CF patients may be established by answering the following questions: is a patient colonised by different genotypes at the same time, and is there a relationship between the colonisation 
typing pattern and the evolution of the disease? Sequential and multiple isolates of $A$. fumigatus from recent and long-term colonised patients were typed in an attempt to answer these questions. RAPD, which has largely been used to assess the biodiversity in different pathogenic fungi including A. fumigatus [7-14, 22, 23], and SSDP, a PCR-based typing method which uses five sets of primers [15], were used in combination, and results were compared to clinical data.

\section{Patients and methods}

\section{Patients}

From Dec. 1995 to July 1997, seven CF patients (1120 years old) followed in two separate units (Paediatric Department and Pneumology Clinic) of Angers hospital (France) were surveyed for colonisation of their respiratory tract by A. fumigatus and for the occurrence of serum antibodies directed against this fungus. Sputum and serum samples were collected during the routine annual clinical visit or during an admission to hospital because of exacerbation of their pulmonary disease. The patients' clinical data - dates of birth, of CF diagnosis and of first colonisation of the airways by A. fumigatus - are indicated in Table 1. Antifungal treatments with itraconazole are shown in Tables 2 and 3. For some patients, earlier serum samples were analysed retrospectively.

\section{Serological tests}

Conventional serological tests were used for the detection of specific antibodies to A. fumigatus. Total antibodies were detected by counterimmuno-electrophoresis (CIE) [24] with culture filtrate antigens of $A$. fumigatus (BioRad Diagnostics Pasteur). Antibodies to the catalase antigen were determined by gel double immunodiffusion [25] with somatic antigens of $A$. fumigatus (BioRad Diagnostics Pasteur). Precipitin lines with catalase activity were investigated by the addition of hydrogen peroxide to the gel.

\section{A. fumigatus isolates}

Samples of lower respiratory tract secretions, provided either by expectoration or by nasotracheal aspiration, were inoculated on yeast extract-peptone-dextrose (YEPD) agar plates containing $(\mathrm{g} / \mathrm{L})$ yeast extract (5), peptone (10), glucose (20), chloramphenicol (1) and agar (20), and incubated at $37^{\circ} \mathrm{C} ; 100 \mu \mathrm{l}$ of the samples were plated directly or after digestion for $30 \mathrm{~min}$ at $37^{\circ} \mathrm{C}$ with an equal volume of 2,3-dihydroxy1,4-dithiolbutane (Digest-EUR; Eurobio, les Ulis, France) followed by a 1 in 10 dilution in sterile distilled water [2]. Two plates were used for each sample and all colonies (with a maximum of five colonies from each sample) from the primary cultures were isolated by plate microscopy before sporulation. Thus, a total of 101 isolates was collected from the

Table 1. Clinical data and serological profile of CF patients colonised with A. fumigatus

\begin{tabular}{|c|c|c|c|c|c|c|}
\hline \multirow[b]{2}{*}{ Patient } & \multirow[b]{2}{*}{ Year of birth } & \multirow[b]{2}{*}{$\begin{array}{l}\text { Year of diagnosis } \\
\text { of } \mathrm{CF}\end{array}$} & \multirow[b]{2}{*}{$\begin{array}{l}\text { Date of first isolation } \\
\text { of A. fumigatus }\end{array}$} & \multicolumn{3}{|c|}{ Serodiagnosis of aspergillosis } \\
\hline & & & & Date & $\begin{array}{l}\text { Precipitin lines to } \\
\text { A. fumigatus* }\end{array}$ & $\begin{array}{l}\text { Anti-catalase } \\
\text { antibodies }\end{array}$ \\
\hline A & 1979 & 1982 & Dec. 1995 & $\begin{array}{l}06 / 12 / 95 \\
25 / 09 / 96\end{array}$ & $\begin{array}{l}0 \\
0\end{array}$ & $\begin{array}{l}- \\
-\end{array}$ \\
\hline B & 1975 & 1978 & Dec. 1995 & $\begin{array}{l}14 / 05 / 95^{\dagger} \\
09 / 09 / 96 \\
23 / 06 / 97\end{array}$ & $\begin{array}{l}0 \\
1 \\
1\end{array}$ & $\begin{array}{l}- \\
+ \\
+\end{array}$ \\
\hline $\mathrm{C}$ & 1975 & 1992 & Dec. 1996 & $\begin{array}{l}06 / 12 / 96 \\
22 / 02 / 97\end{array}$ & $\begin{array}{l}0 \\
0\end{array}$ & $\begin{array}{l}- \\
-\end{array}$ \\
\hline $\mathrm{D}$ & 1985 & 1985 & Oct. 1991 & $\begin{array}{l}26 / 06 / 96 \\
24 / 09 / 96\end{array}$ & $\begin{array}{l}0 \\
0\end{array}$ & $\begin{array}{l}- \\
-\end{array}$ \\
\hline $\mathrm{E}$ & 1978 & 1983 & 1989 & $\begin{array}{l}20 / 08 / 95^{\dagger} \\
06 / 12 / 95 \\
03 / 01 / 96 \\
17 / 01 / 97\end{array}$ & $\begin{array}{l}0 \\
1 \\
2 \\
1\end{array}$ & $\begin{array}{l}- \\
+ \\
+ \\
+\end{array}$ \\
\hline $\mathrm{F}$ & 1979 & 1984 & Jan. 1990 & $\begin{array}{l}23 / 12 / 91^{\dagger} \\
12 / 02 / 92^{\dagger} \\
03 / 02 / 93^{\dagger} \\
02 / 02 / 94^{\dagger} \\
01 / 03 / 95^{\dagger} \\
28 / 02 / 96\end{array}$ & $\begin{array}{l}0 \\
1 \\
1 \\
2 \\
2 \\
2\end{array}$ & $\begin{array}{l}- \\
- \\
- \\
+ \\
+ \\
+\end{array}$ \\
\hline G & 1983 & 1987 & June 1992 & $\begin{array}{l}24 / 11 / 93^{\dagger} \\
08 / 12 / 95 \\
19 / 02 / 96\end{array}$ & $\begin{array}{l}1 \\
1 \\
1\end{array}$ & $\begin{array}{l}- \\
+ \\
+\end{array}$ \\
\hline
\end{tabular}

\footnotetext{
* Number of precipitin lines obtained by counterimmuno-electrophoresis

${ }^{\dagger}$ Samples analysed retrospectively.
} 
Table 2. Genotypes of $A$. fumigatus isolates from sputum of recently colonised patients

\begin{tabular}{|c|c|c|c|c|c|c|c|c|c|c|}
\hline \multirow[b]{2}{*}{ Patient } & \multirow{2}{*}{$\begin{array}{l}\text { Date of } \\
\text { isolation }\end{array}$} & \multirow[b]{2}{*}{ IHEM no. } & \multicolumn{5}{|c|}{ SSDP analysis } & \multirow{2}{*}{$\begin{array}{l}\text { SSDP } \\
\text { type }\end{array}$} & \multirow{2}{*}{$\begin{array}{c}\text { RAPD } \\
\text { type }\end{array}$} & \multirow{2}{*}{$\begin{array}{l}\text { Overall } \\
\text { genotype }\end{array}$} \\
\hline & & & 1 & 2 & 3 & 4 & 5 & & & \\
\hline \multirow[t]{6}{*}{ A } & $06 / 12 / 95$ & 9909 & - & - & + & + & + & 28 & 3 & 1 \\
\hline & & 9910 & - & - & + & + & + & 28 & 3 & 1 \\
\hline & & 9911 & + & - & - & + & + & 30 & 2 & 2 \\
\hline & & 9912 & + & + & - & - & + & 21 & 13 & 3 \\
\hline & & 9913 & + & - & + & + & + & 26 & 2 & 4 \\
\hline & $25 / 09 / 96$ & 13831 & + & - & - & + & + & 30 & 9 & 5 \\
\hline \multirow[t]{10}{*}{ B } & $08 / 12 / 95$ & 9914 & - & - & - & - & + & 24 & 14 & 6 \\
\hline & & 9915 & - & - & - & + & + & 32 & 15 & 7 \\
\hline & & 9916 & + & - & + & + & + & 26 & 16 & 8 \\
\hline & & 9917 & - & + & - & + & + & 31 & 4 & 9 \\
\hline & & 9918 & - & + & - & + & + & 31 & 4 & 9 \\
\hline & $12 / 01 / 96$ & 9967 & + & - & - & + & + & 30 & 17 & 10 \\
\hline & & 9968 & - & - & + & + & + & 28 & 16 & 11 \\
\hline & $09 / 09 / 96$ & 13832 & + & - & - & + & + & 30 & 2 & 2 \\
\hline & $23 / 06 / 97$ & 13833 & + & + & - & + & + & 29 & 9 & 12 \\
\hline & & 13834 & + & - & - & + & + & 30 & 16 & 13 \\
\hline \multirow[t]{4}{*}{$\mathrm{C}$} & $06 / 12 / 96$ & 13862 & + & - & - & + & + & 30 & 2 & 2 \\
\hline & & 13863 & + & - & - & + & + & 30 & 2 & 2 \\
\hline & $22 / 02 / 97$ & 13864 & + & - & - & + & + & 30 & 2 & 2 \\
\hline & & 13865 & + & - & - & + & + & 30 & 2 & 2 \\
\hline
\end{tabular}

seven CF patients. Eight isolates originating from earlier sputum samples from patients $\mathrm{F}$ and $\mathrm{G}$, that had been cryopreserved in this laboratory were also analysed. All isolates were deposited at the BCCM/ IHEM Culture Collection (Brussels, Belgium). The origins of the isolates (nature of the samples and date of isolation) are summarised in Tables 2 and 3.

\section{Preparation of genomic DNA}

The isolates were cultivated in YEPD liquid medium in $25-\mathrm{ml}$ Erlenmeyer flasks and incubated for $36 \mathrm{~h}$ with agitation $(150 \mathrm{rpm})$. Mycelia were harvested by filtration under vacuum and transferred to 2-ml screwcapped microtubes containing $700 \mu \mathrm{l}$ of glass beads ( $0.5 \mathrm{~mm}$ diameter), $600 \mu 1$ of lysis buffer ( $50 \mathrm{~mm}$ Tris$\mathrm{HCl}$ buffer, $\mathrm{pH} 8$, containing $50 \mathrm{mM}$ EDTA and sodium dodecyl sulphate 3\%) and $600 \mu \mathrm{l}$ of phenol: chloroform: iso-amyl alcohol (25:24:1). The tubes were agitated for $2 \mathrm{~min}$ in a cell disrupter (Minibeadbeater; Biospec, Bartlesville, OK, USA). Lysates were then incubated at $65^{\circ} \mathrm{C}$ for $60 \mathrm{~min}$. After centrifugation the DNA was precipitated with ethanol, dried and resuspended in sterile distilled water.

\section{$R A P D$}

PCR was performed in a Perkin Elmer Gene Amp 9600 Thermocycler programmed as follows (low stringency conditions): $2 \mathrm{~min}$ at $93^{\circ} \mathrm{C}$, followed by 40 cycles of $20 \mathrm{~s}$ at $93^{\circ} \mathrm{C}$ for denaturing, $1 \mathrm{~min}$ at $40^{\circ} \mathrm{C}$ for annealing and $30 \mathrm{~s}$ at $72^{\circ} \mathrm{C}$ for elongation, and a final extension of $6 \mathrm{~min}$ at $72^{\circ} \mathrm{C}$. The reaction mixture $(50 \mu \mathrm{l})$ contained $10 \mathrm{ng}$ of genomic DNA and consisted of $50 \mathrm{~mm}$ Tris-HC1 buffer, $\mathrm{pH} 8.3,50 \mathrm{mM} \mathrm{KC1}, 3 \mathrm{mM}$ $\mathrm{MgCl}_{2}$, bovine serum albumin $0.1 \mathrm{mg} / \mathrm{ml}, 200 \mu \mathrm{M}$ of each desoxyribonucleotide triphosphate (dNTP), 20 pmoles of primer NS3 (5'-GCAAGTCTGGTGC CAGCAGCC-3'; Pharmacia Biotech, Roosendaal, The Netherlands) and Taq DNA polymerase (Boehringer Mannheim, Brussels, Belgium) 2.5 U. For each amplification, a negative control without DNA was treated under the same conditions.

Amplification products were separated by agarose 1.5\% gel electrophoresis in TBE buffer $45 \mathrm{mM}$ Tris, $45 \mathrm{~mm}$ boric acid, $1 \mathrm{mM} \mathrm{Na} 2$ EDTA) together with mol. wt standards (mix of $\lambda$ DNA BstEII and $\phi X 174$ DNA Hae III digests, both from New England Biolabs, Westburg, The Netherlands). Gels were stained for $1 \mathrm{~h}$ in ethidium bromide $0.5 \mu \mathrm{g} / \mathrm{ml}$, de-stained for $20 \mathrm{~min}$ and examined under UV illumination.

Reproducibility of the method was assessed by performing RAPD with DNA from different generations of the same isolates, after freeze-drying or liquid nitrogen preservation and after subcloning the isolates by the dilution technique. The discriminatory power (0.94) was calculated according to Hunter [26] with 13 unrelated strains from human and animal origins. The criterion used to establish a different type was the presence or absence of three consistent bands.

\section{SSDP analysis}

SSDP analysis was performed essentially as described by Mondon et al. [15] with slight modifications. The primers used, i.e., Afpl (5'-TTGGGGAGATTACC GAACTGG- $\left.3^{\prime}\right)$ and Afp2 (5'-CCTTGACAACCGTCC CATTTC-3 $\left.{ }^{\prime}\right)$ for marker SSDP 1, AfMp1 (5'CAGTTCCCGTCTTGACCTC- $\left.3^{\prime}\right)$ and AfMp2 (5'CAGTTCCCGTTTTCCTAGTA-3') for marker 2, 
Table 3. Genotypes of A. fumigatus isolates from long-term colonised patients

\begin{tabular}{|c|c|c|c|c|c|c|c|c|c|c|}
\hline \multirow[b]{2}{*}{ Patient } & \multirow{2}{*}{$\begin{array}{l}\text { Date of } \\
\text { isolation }\end{array}$} & \multirow[b]{2}{*}{ IHEM no. } & \multicolumn{5}{|c|}{ SSDP analysis } & \multirow{2}{*}{$\begin{array}{l}\text { SSDP } \\
\text { type }\end{array}$} & \multirow{2}{*}{$\begin{array}{l}\text { RAPD } \\
\text { type }\end{array}$} & \multirow{2}{*}{$\begin{array}{c}\text { Overall } \\
\text { genotype }\end{array}$} \\
\hline & & & 1 & 2 & 3 & 4 & 5 & & & \\
\hline $\mathrm{D}$ & $26 / 06 / 96$ & 13868 & + & + & - & + & + & 29 & 9 & 12 \\
\hline & & 13869 & + & + & - & + & + & 29 & 9 & 12 \\
\hline & & 13870 & + & + & - & + & + & 29 & 9 & 12 \\
\hline & & 13871 & + & + & - & + & + & 29 & 9 & 12 \\
\hline & $24 / 09 / 96$ & 13872 & + & + & - & + & + & 29 & 9 & 12 \\
\hline & & 13873 & + & + & - & + & + & 29 & 4 & 14 \\
\hline & & 13874 & + & + & - & + & + & 29 & 9 & 12 \\
\hline & & 13875 & + & + & - & + & + & 29 & 9 & 12 \\
\hline & & 13876 & + & + & - & + & + & 29 & 9 & 12 \\
\hline $\mathrm{E}$ & $06 / 12 / 95$ & $9919^{\dagger}$ & - & - & - & + & + & 32 & 16 & 15 \\
\hline & & $9920^{\dagger}$ & + & - & - & + & + & 30 & 2 & 2 \\
\hline & & $9921^{\dagger}$ & + & - & - & + & + & 30 & 16 & 13 \\
\hline & & $9922^{\dagger}$ & - & - & - & + & + & 32 & 16 & 15 \\
\hline & $15 / 12 / 95$ & 9923 & - & - & - & + & + & 32 & 4 & 16 \\
\hline & & 9924 & + & + & - & + & + & 29 & 4 & 14 \\
\hline & & 9925 & + & - & - & + & + & 30 & 4 & 17 \\
\hline & & 9926 & + & - & - & + & + & 30 & 2 & 2 \\
\hline & & 9927 & + & + & - & + & + & 29 & 2 & 18 \\
\hline & $22 / 12 / 95$ & 9928 & + & - & - & + & + & 30 & 2 & 2 \\
\hline & & 9929 & + & - & - & + & + & 30 & 2 & 2 \\
\hline & & 9930 & + & - & - & + & + & 30 & 18 & 19 \\
\hline & & 9931 & + & - & - & + & + & 30 & 2 & 2 \\
\hline & & 9932 & + & - & - & + & + & 30 & 2 & 2 \\
\hline & $03 / 01 / 96$ & 9969 & + & + & - & + & + & 29 & 2 & 18 \\
\hline & & 9970 & + & - & - & + & + & 30 & 2 & 2 \\
\hline & & 9971 & - & - & - & + & + & 32 & 2 & 20 \\
\hline & & 9972 & + & - & - & + & + & 30 & 2 & 2 \\
\hline & & 9973 & + & - & - & + & + & 30 & 18 & 19 \\
\hline & $02 / 12 / 96$ & 13835 & - & - & - & + & + & 32 & 4 & 16 \\
\hline & $14 / 01 / 97$ & 13836 & + & - & - & + & + & 30 & 2 & 2 \\
\hline & & 13837 & + & - & - & + & + & 30 & 2 & 2 \\
\hline & & 13838 & + & + & - & + & + & 29 & 2 & 18 \\
\hline & & 13839 & + & - & - & + & + & 30 & 2 & 2 \\
\hline & $15 / 01 / 97$ & 13840 & + & - & - & + & + & 30 & 2 & 2 \\
\hline & $17 / 01 / 97$ & 13841 & + & - & - & + & + & 30 & 2 & 2 \\
\hline & & 13842 & + & - & - & + & + & 30 & 2 & 2 \\
\hline & & 13843 & + & - & - & + & + & 30 & 2 & 2 \\
\hline & $24 / 03 / 97$ & 13844 & + & + & - & + & + & 29 & 2 & 18 \\
\hline & & 13845 & + & - & - & + & + & 30 & 2 & 2 \\
\hline & & 13846 & + & - & - & + & + & 30 & 2 & 2 \\
\hline & & 13847 & + & + & - & + & + & 29 & 2 & 18 \\
\hline & & 13848 & - & - & + & + & + & 28 & 2 & 21 \\
\hline $\mathrm{F}$ & $23 / 12 / 91$ & $9997^{*}$ & + & + & + & + & + & 25 & 16 & 22 \\
\hline & $12 / 02 / 92$ & $9998^{*}$ & + & - & - & + & + & 30 & 16 & 13 \\
\hline & $03 / 02 / 93$ & $9999^{*}$ & + & - & - & + & + & 30 & 18 & 19 \\
\hline & $02 / 02 / 94$ & $10000^{*}$ & + & - & - & + & + & 30 & 2 & 2 \\
\hline & $10 / 08 / 94$ & $10001^{*}$ & + & - & - & + & + & 30 & 2 & 2 \\
\hline & $01 / 03 / 95$ & $10002^{*}$ & + & + & - & + & + & 29 & 18 & 23 \\
\hline & $28 / 02 / 96$ & 10003 & + & - & - & + & + & 30 & 2 & 2 \\
\hline & & 10004 & + & - & - & + & + & 30 & 2 & 2 \\
\hline & & 10005 & + & + & - & + & + & 29 & 18 & 23 \\
\hline & & 10006 & + & - & - & + & + & 30 & 2 & 2 \\
\hline & $24 / 11 / 93$ & $10008^{*}$ & + & + & - & + & + & 29 & 2 & 18 \\
\hline & $08 / 02 / 95$ & $10009^{*}$ & + & + & - & + & + & 29 & 9 & 12 \\
\hline & $19 / 02 / 96$ & 10012 & + & + & - & + & + & 29 & 2 & 18 \\
\hline & & 10013 & + & - & - & + & + & 30 & 2 & 2 \\
\hline & & 10014 & - & - & - & - & + & 24 & 2 & 24 \\
\hline & & 10015 & + & - & - & + & + & 30 & 2 & 2 \\
\hline & $22 / 02 / 96$ & 10016 & + & - & - & + & + & 30 & 2 & 2 \\
\hline & & 10017 & + & - & - & + & + & 30 & 2 & 2 \\
\hline & & 10018 & + & - & - & + & + & 30 & 18 & 19 \\
\hline & & 10019 & + & - & - & + & + & 30 & 2 & 2 \\
\hline & $01 / 03 / 96$ & 10021 & + & - & - & + & + & 30 & 2 & 2 \\
\hline & & 10022 & - & - & - & + & + & 24 & 4 & 25 \\
\hline & & 10023 & + & - & - & + & + & 30 & 2 & 2 \\
\hline & $07 / 03 / 96$ & 10028 & + & - & - & + & + & 30 & 2 & 2 \\
\hline & & 10029 & + & - & - & + & + & 30 & 2 & 2 \\
\hline & & 10030 & + & - & - & + & + & 30 & 2 & 2 \\
\hline & $13 / 03 / 96$ & 10031 & + & - & - & + & + & 30 & 2 & 2 \\
\hline & & 10032 & + & - & - & + & + & 30 & 2 & 2 \\
\hline & & 10033 & + & - & - & + & + & 30 & 2 & 2 \\
\hline & & 10034 & + & - & - & + & + & 30 & 2 & 2 \\
\hline
\end{tabular}


Table 3. (Continued).

\begin{tabular}{|c|c|c|c|c|c|c|c|c|c|c|}
\hline \multirow[b]{2}{*}{ Patient } & \multirow{2}{*}{$\begin{array}{l}\text { Date of } \\
\text { isolation }\end{array}$} & \multirow[b]{2}{*}{ IHEM no. } & \multicolumn{5}{|c|}{ SSDP analysis } & \multirow{2}{*}{$\begin{array}{l}\text { SSDP } \\
\text { type }\end{array}$} & \multirow{2}{*}{$\begin{array}{l}\text { RAPD } \\
\text { type }\end{array}$} & \multirow{2}{*}{$\begin{array}{l}\text { Overall } \\
\text { genotype }\end{array}$} \\
\hline & & & 1 & 2 & 3 & 4 & 5 & & & \\
\hline & \multirow[t]{2}{*}{$20 / 03 / 96$} & 10037 & + & - & - & + & + & 30 & 2 & 2 \\
\hline & & 10038 & + & - & - & + & + & 30 & 2 & 2 \\
\hline & \multirow[t]{2}{*}{$27 / 03 / 96$} & 10041 & + & + & - & + & + & 29 & 2 & 18 \\
\hline & & 10042 & + & + & - & + & + & 29 & 2 & 18 \\
\hline & $25 / 04 / 96$ & 13849 & + & - & - & + & + & 30 & 2 & 2 \\
\hline & \multirow[t]{4}{*}{$03 / 05 / 96$} & 13850 & + & - & - & + & + & 30 & 2 & 2 \\
\hline & & 13851 & + & - & - & + & + & 30 & 2 & 2 \\
\hline & & 13852 & + & - & - & + & + & 30 & 2 & 2 \\
\hline & & 13853 & + & - & - & + & + & 30 & 2 & 2 \\
\hline & \multirow[t]{2}{*}{$07 / 05 / 96$} & 13854 & + & - & - & + & + & 30 & 2 & 2 \\
\hline & & 13855 & + & - & - & + & + & 30 & 2 & 2 \\
\hline & \multirow[t]{2}{*}{$24 / 05 / 96$} & 13856 & - & - & - & + & + & 32 & 4 & 16 \\
\hline & & 13857 & + & + & - & + & + & 29 & 2 & 18 \\
\hline & $31 / 05 / 96$ & 13858 & + & - & - & + & + & 30 & 2 & 2 \\
\hline & \multirow[t]{3}{*}{$11 / 07 / 96$} & 13859 & + & + & - & + & + & 29 & 2 & 18 \\
\hline & & 13860 & + & - & - & + & + & 30 & 2 & 2 \\
\hline & & 13861 & + & + & - & + & + & 29 & 2 & 18 \\
\hline
\end{tabular}

Patient E was treated with itraconazole in June 1996, and patient F fom Aug. 1994 to Jan. 1995.

$\dagger$ Isolates obtained from bronchial aspirates (all other isolates were from sputum samples).

Isolates analysed retrospectively.

Afd1 (5'-GTATTGCCCTATAACTTCTT-3') and Afd2 (5'-GTATTGCCCTATTCCCAAAG-3') for marker 3, Afs4 (5'-GTATTGCCCTAGCTTACTAA-3') and Afr4 $\left(5^{\prime}\right.$-GTATTGCCCTATTACTAAAG-3') for marker 4 and Afr5 (5'-GTATTGCCCTAAGTTCTA-3') and Afr5 (5'-GTATTGCCCTAGCTTGCTAA-3') for marker 5 , were synthesised by Genset SA (Paris, France). Amplification reactions were performed in a 50- $\mu 1$ volume containing buffer (50 mM Tris-HC1, $\mathrm{pH} 8.3$ ) $50 \mathrm{mM} \mathrm{KC1}$, bovine serum albumin $0.1 \mathrm{mg} / \mathrm{ml}, 3 \mu \mathrm{M}$ $\mathrm{MgC1}_{2}, 200 \mathrm{mM}$ of each dNTP, 10 pmoles of each primer, Taq DNA polymerase $2.5 \mathrm{U}$ and genomic DNA $50 \mathrm{ng}$. The thermocycler was programmed for an initial heat denaturation step of $3 \mathrm{~min}$ at $94^{\circ} \mathrm{C}$, followed by 30 cycles of $20 \mathrm{~s}$ at $94^{\circ} \mathrm{C}, 30 \mathrm{~s}$ at $55^{\circ} \mathrm{C}$ and $1 \mathrm{~min}$ at $72^{\circ} \mathrm{C}$. Amplification products were separated by electrophoresis on agarose $1.5 \%$ gels, stained with ethidium bromide and visualised under UV light. Isolates were classified according to the presence or absence of each band that was specifically amplified.

\section{Classification of the genotypes}

RAPD types with primer types NS3 and SSDP were numbered according to Rodriguez et al. [14] and Mondon et al. [15] respectively. The overall genotypes obtained by combining the results of the two typing methods were designated 1-25.

\section{Results}

Serology

Antibodies to A. fumigatus were detected in four patients whose sera contained one or two precipitating antibodies by CIE and with specific antibodies to the catalase antigen (Table 1). Serology was positive subsequent to the initial colonisation of the airways by $A$. fumigatus, with a delay varying from 9 months to 6 years. For patients $\mathrm{F}$ and $\mathrm{G}$, anti-catalase antibodies were not detected in the first positive serum sample, but only 2 years later.

\section{Genotype analysis}

Electrophoretic analysis of the amplicons generated by primer NS3 revealed numerous consistent bands with mol. wt of $600-1400 \mathrm{bp}$. This primer permitted the differentiation of the isolates into 10 RAPD types (Tables 2 and 3). Several genotypes were simultaneously or successively identified, or both, in all but one of the patients. Moreover, several RAPD types were common to some patients. The RAPD type 2 was the most frequent, isolated from all patients except patient $\mathrm{D}$, occasionally in patients $\mathrm{A}$ and $\mathrm{B}$ or predominantly in the others.

The combination of presence $(+)$ or absence $(-)$ of each single amplified band defined the SSDP types (Tables 2 and 3). The five sets of primers gave rise to nine different SSDP types. Seven SSDP types were identified for patient $B$, four for patients $A, E$ and $G$, three for patient $F$ and two for patient $D$, whereas patient $\mathrm{C}$ was colonised by a unique SSDP type. Some types were also found to be common among different patients. SSDP types 29 and 30 were the most frequent, isolated from five and six patients respectively.

Combination of the data from RAPD and SSDP resulted in a marked increase in discriminatory power; 25 overall types were defined from the 109 isolates (Tables 2 and 3). Among these genotypes, 14 were 
represented by a single isolate and three were identified only twice. Conversely, overall types 2, 18 and 12 were the most common, represented by 53, 12 and 9 isolates, respectively.

\section{Comparison of typing results with clinical and serological data}

Considering the date of the first isolation of $A$. fumigatus, the patients were classified into two groups (Table 1). Patients A, B and C had been colonised by the fungus for $<1$ year at the time of the survey, whereas the other four patients had been colonised for several years, and bronchial secretions from these latter patients were sampled at different dates in the course of the survey (Tables 2 and 3 ).

Isolates from recently colonised patients belonged to a large diversity of overall genotypes. Patients A and B harboured several genotypes in the same sample. Five different overall types were identified from the six isolates originating from sputum samples of patient A, and nine from the 10 isolates obtained from patient $\mathrm{B}$. Conversely, patient $\mathrm{C}$ was colonised by a unique genotype, overall type 2, which was the only one common to these three patients. In this group, one patient (patient B) presented with antibodies to $A$. fumigatus. For this patient, the date of the first positive serological test, with a unique precipitin line by CIE and the presence of anti-catalase antibodies in the immunodiffusion assay, coincided with the appearance of the overall type 2 in the bronchial secretions.

For patients chronically colonised by A. fumigatus, a large number of multiple isolates were available. Compared with recently colonised patients, and considering the greater number of isolates studied, the number of overall types observed in this group of patients was limited: two different types were identified from nine isolates for patient D, 10 from 34 isolates for patient $\mathrm{E}$, five from 10 isolates for patient $\mathrm{F}$, and seven from 37 isolates for patient G. Except for types 2, 12 and 13 , no genotype was found to be common to the two groups of patients. Type 12 was predominant in the isolates from patient D. For the other patients, different genotypes sometimes co-existed in a single sample, but one dominant genotype (type 2) tended to coincide with prolonged colonisation. Indeed, when colonisation was present for $>3$ years, this genotype represented $52 \%$ (17 of 33 ), $63 \%$ (5 of 8 ) and $71 \%$ (25 of 35 ) of the isolates from patients $\mathrm{E}, \mathrm{F}$ and $\mathrm{G}$, respectively. Moreover, in these three patients, genotype 2 emerged simultaneously with the appearance of anti-catalase antibodies to $A$. fumigatus (Tables 1 and 3 ). For patients $\mathrm{E}$ and $\mathrm{F}$, who were treated with itraconazole, type 2 was not detected in the isolates originating from the bronchial secretions sampled at the end of the treatment, but re-appeared in the subsequent samples.

\section{Discussion}

Previous studies have highlighted the importance of combining different molecular typing methods to get a better understanding of strain relatedness and of the epidemiology of A. fumigatus infections [8, 11, 14]. Therefore, the present study used two different molecular typing methods, RAPD and SSDP, to type 109 A. fumigatus isolates from seven CF patients. As expected, combining the results of the two methods resulted in an increase in the discriminatory power. The two methods were usually in good agreement. However, the concordance was not absolute, for instance, isolates belonging to RAPD types 4 or 16 were equally distributed between five different SSDP types. Thus, 25 overall genotypes were identified, whereas RAPD or SSDP alone detected only 10 and 9 different types, respectively.

The results also show the value of having multiple isolates available to establish a typing colonisation pattern. The analysis of sequential $A$. fumigatus isolates revealed that two $\mathrm{CF}$ patients harboured a unique genotype, whereas several genotypes were simultaneously or successively, or both, displayed for the other patients. Therefore, these results are in agreement with the studies of Verweij et al. [20] and Rath et al. [21], in which analysis of sequential isolates showed that some CF patients exhibited a predominant genotype and others had multiple genotypes. Furthermore, the number of genotypes identified in the patients in the present study was rather limited, compared with the diversity of genotypes found in the environment as well as in other A. fumigatus diseases [7, 14, 15, 17, 27]. For example, combining RAPD and SSDP allowed the identification of 21 overall genotypes among 27 environmental strains tested, and no dominant genotype was observed [14]. Similarly, an important biodiversity was also noted for pulmonary transplant recipients colonised by $A$. fumigatus, whereas most patients with invasive aspergillosis harboured a more stable genotype which differed from one patient to another in epidemiologically unrelated individuals [14].

The results of the present study may appear to conflict with those reported by Debeaupuis et al. [28], as they did not find any clustering between environmental isolates and clinical isolates from invasive aspergillosis or CF patients. Nevertheless, the typing method used, RFLP followed by Southern hybridisation with a species-specific retrotransposon-like sequence, is highly discriminating, allowing true fingerprinting of the strains, but perhaps too discriminating to reveal such a clustering. Moreover, as in studies by Verweij et al. [20] and Rath et al. [21], the duration of colonisation of patients by A. fumigatus was not taken into account.

In the present study, by typing multiple and sequential isolates in relation to the duration of colonisation, it was found that the colonisation patterns differed greatly 
between recently colonised patients and chronically colonised patients, and that a dominant genotype tended to settle in the latter. Two of the recently colonised patients harboured multiple genotypes even in the same sample. Conversely, a limited number of genotypes was detected in long-term colonised patients. Only three genotypes were common to both groups of patients, and among them, genotype 2 was found to be largely dominant in three of the chronically colonised patients. Furthermore, among the recently colonised patients, the only individual who did not exhibit various genotypes was colonised exclusively by genotype 2 .

Interestingly, this genotype was detected only once among 27 environmental strains, as well as in a unique patient with invasive aspergillosis, and accounted for only three of the 37 isolates from this patient [14]. Thus, this genotype, occasionally found in the environment and in invasive aspergillosis, seems to be preferentially associated with colonisation of the airways in $\mathrm{CF}$ patients and progressively selected in prolonged colonisation. Similar findings have been reported for $P$. aeruginosa in $\mathrm{CF}$ patients. Indeed, chronic infection of the airways with $P$. aeruginosa corresponds to the emergence of a mucoid phenotype of this bacterium which is more immunogenic and more pathogenic [29]. In A. fumigatus, it has been demonstrated in experimental models of invasive aspergillosis that there are differences in virulence between strains, with clinical isolates being more virulent than environmental strains, suggesting that pathogenicity not only depends on the immune status of the host but also on fungus-related factors [30, 31].

Anti-catalase antibodies are standard serological markers for A. fumigatus diseases and they are routinely detected by immunodiffusion methods. In CF, they are usually found in a minority of patients colonised by $A$. fumigatus $[2,32]$ and their presence in these patients was shown to be related to decreased pulmonary function [32]. In vitro, all the strains of A. fumigatus from $\mathrm{CF}$ patients that were tested for catalase activity by a spectrophotometric assay produced varying levels of the enzyme (unpublished data). However, perhaps in relation to the well-known low sensitivity of agar gel double immunodiffusion, anti-catalase antibodies were detected only in patients colonised by genotype 2 . Indeed, in the chronically colonised patients, the appearance of serum anti-catalase antibodies coincided with the emergence of this genotype in bronchial secretions. Furthermore, anti-catalase antibodies were detected in a patient recently colonised by this genotype of $A$. fumigatus. However, these results are not absolutely conclusive, as no anti-catalase antibodies were found for patient $\mathrm{C}$, who was colonised exclusively by type 2 , perhaps in relation to particular host factors controlling the immune response. Further studies, including a larger number of patients from different geographical areas, are now being undertaken to confirm this genotypic selection of $A$. fumigatus in the course of colonisation of the airways in $\mathrm{CF}$ patients.

This work was supported by a grant from the French Ministry of Health (Programme Hospitalier de Recherche Clinique 1997).

\section{References}

1. Koch C, Høiby N. Pathogenesis of cystic fibrosis. Lancet 1993; 341: $1065-1069$.

2. Cimon B, Carrère J, Chazalette J-P et al. Fungal colonisation and immune response to fungi in cystic fibrosis. J Mycol Med 1995; 5: 211-216.

3. Denning DW, Clemons KV, Hanson LH, Stevens DA. Restriction endonuclease analysis of total cellular DNA of Aspergillus fumigatus isolates of geographically and epidemiologically diverse origin. J Infect Dis 1990; 162: 1151-1158.

4. Burnie JP, Coke A, Matthews RC. Restriction endonuclease analysis of Aspergillus fumigatus DNA. J Clin Pathol 1992; 45: $324-327$.

5. Birch M, Nolard N, Shankland GS, Denning DW. DNA typing of epidemiologically-related isolates of Aspergillus fumigatus. Epidemiol Infect 1995; 114: 161-168.

6. Girardin H, Latgé J-P, Srikantha T, Morrow B, Soll DR. Development of DNA probes for fingerprinting Aspergillus fumigatus. J Clin Microbiol 1993; 31: 1547-1554.

7. Tang CM, Cohen J, Rees AJ, Holden DW. Molecular epidemiological study of invasive pulmonary aspergillosis in a renal transplantation unit. Eur $J$ Clin Microbiol Infect Dis 1994; 13: 318-321.

8. Anderson MJ, Gull K, Denning DW. Molecular typing by random amplification of polymorphic DNA and M13 southern hybridisation of related paired isolates of Aspergillus fumigatus. J Clin Microbiol 1996; 34: 87-93.

9. Aufauvre-Brown A, Cohen J, Holden DW. Use of randomly amplified polymorphic DNA markers to distinguish isolates of Aspergillus fumigatus. J Clin Microbiol 1992; 30: 2991-2993.

10. Loudon KW, Burnie JP, Coke AP, Matthews RC. Application of polymerase chain reaction to fingerprinting Aspergillus fumigatus by random amplification of polymorphic DNA. $J$ Clin Microbiol 1993; 31: 1117-1121.

11. Lin D, Lehmann PF, Hamory BH et al. Comparison of three typing methods for clinical and environmental isolates of Aspergillus fumigatus. J Clin Microbiol 1995; 33: 1596-1601.

12. Loudon KW, Burnie JP. Comparison of three typing methods for clinical and environmental isolates of Aspergillus fumigatus. J Clin Microbiol 1995; 33: 3362-3363.

13. Leenders A, van Belkum A, Janssen $\mathrm{S}$ et al. Molecular epidemiology of apparent outbreak of invasive aspergillosis in a hematology ward. J Clin Microbiol 1996; 34: 345-351.

14. Rodriguez E, Symoens F, Mondon P et al. Combination of three typing methods for the molecular epidemiology of Aspergillus fumigatus infections. European Research Group on Biotype and Genotype of Aspergillus. J Med Microbiol 1999; 48: 181-194.

15. Mondon P, Brenier M-P, Symoens F et al. Molecular typing of Aspergillus fumigatus strains by sequence-specific DNA primer (SSDP) analysis. FEMS Immunol Med Microbiol 1997; 17: 95-102.

16. Bart-Delabesse E, Humbert J-F, Delabesse E, Bretagne S. Microsatellite markers for typing Aspergillus fumigatus isolates. J Clin Microbiol 1998; 36: 2413-2418.

17. Girardin H, Sarfati J, Traoré F, Dupouy Camet J, Derouin F, Latgé JP. Molecular epidemiology of nosocomial invasive aspergillosis. J Clin Microbiol 1994; 32: 684-690.

18. Denning DW, Shankland GS, Stevens DA. DNA fingerprinting of Aspergillus fumigatus isolates from patients with aspergilloma. J Med Vet Mycol 1991; 29: 339-342.

19. Girardin H, Sarfati J, Kobayashi H, Bouchara JP, Latgé JP. Use of DNA moderately repetitive sequence to type Aspergillus fumigatus isolates from aspergilloma patients. J Infect Dis 1994; 169: 683-685.

20. Verweij PE, Meis JFGM, Sarfati J, Hoogkamp-Korstanje JAA, Latgé J-P, Melchers WJG. Genotypic characterization of sequential Aspergillus fumigatus isolates from patients with 
cystic fibrosis. J Clin Microbiol 1996; 34: 2595-2597.

21. Rath PM, Ratjen F, Ansorg R. Genetic diversity among isolates of Aspergillus fumigatus in patients with cystic fibrosis. Zentral Bakteriol 1997; 285: 450-455.

22. White TJ, Bruns T, Lee S, Taylor J. Amplification and direct sequencing of fungal ribosomial RNA genes for phylogenetics. In: Innis MA, Gelfand DH, Sninsky JJ, White TJ (eds) PCR protocols: a guide to methods and applications. San Diego, Academic Press. 1990: 315-322.

23. Symoens F, Bouchara J-P, Heinemann S, Nolard N. Molecular typing of Aspergillus terreus isolates by random amplification of polymorphic DNA. J Hosp Infect 2000; 44: 273-280.

24. Gordon MA, Almy RE, Greene CH, Fenton JW. Diagnostic mycoserology by immunoelectrophoresis: a general, rapid, and sensitive microtechnic. Am J Clin Pathol 1971; 56: 471-474.

25. Kurup VP, Fink JN. Evaluation of methods to detect antibodies against Aspergillus fumigatus. Am J Clin Pathol 1978; 69: 414-417.

26. Hunter PR. Reproducibility and indices of discriminatory power of microbial typing methods. J Clin Microbiol 1990; 28: $1903-1905$.

27. Chazalet V, Debeaupuis J-P, Sarfati J et al. Molecular typing of environmental and patient isolates of Aspergillus fumigatus from various hospital settings. J Clin Microbiol 1998; 36: 1494-1500.

28. Debeaupuis J.-P, Sarfati J, Chazalet V, Latgé J-P. Genetic diversity among clinical and environmental isolates of Aspergillus fumigatus. Infect Immun 1997; 65: 3080-3085.

29. Mahenthiralingam E, Speert DP. Microbial virulence and pathogenesis in cystic fibrosis. In: Bauernfeind A, Marks MI, Strandvik B (eds) Cystic fibrosis pulmonary infections: lessons from around the world. Basel, Birkhäuser Verlag. 1996: 65-83.

30. Mondon P, De Champs C, Donadille A, Ambroise-Thomas P, Grillot R. Variation in virulence of Aspergillus fumigatus strains in a murine model of invasive pulmonary aspergillosis. J Med Microbiol 1996; 45: 186-191.

31. Aufauvre-Brown A, Brown JS, Holden DW. Comparison of virulence between clinical and environmental isolates of Aspergillus fumigatus. Eur J Clin Microbiol Infect Dis 1998; 17: $778-780$

32. Schønheyder H, Jensen T, Laessoe IH, Høiby N, Koch C. Serum antibodies to Aspergillus fumigatus catalase in patients with cystic fibrosis. Eur J Clin Microbiol Infect Dis 1988; 7: 40-44. 